\title{
Peripheral plasma levels of oestradiol-17 $\beta$ and progesterone in the bitch during the oestrous cycle, in normal pregnancy and after dexamethasone treatment
}

\author{
R. Austad, Astrid Lunde and Ø. V. Sjaastad \\ Departments of Physiology and Obstetrics, Veterinary College of Norway, \\ P. Box 8146, Oslo Dep., Oslo 1, Norway
}

\begin{abstract}
Summary. Plasma oestradiol-17ß concentrations in Labradors increased during pro-oestrus to an average maximal concentration of $79.7 \pm 10.9$ (S.D.) $\mathrm{pg} / \mathrm{ml}$, and then fell rapidly. In 6/7 bitches the peak occurred within 1 day of oestrus. No consistent changes in plasma oestradiol levels were observed during pregnancy and at parturition and the values were similar to those in late anoestrus. Plasma progesterone levels did not increase markedly during pro-oestrus. At oestrus, progesterone values rose and maximal concentrations, which varied from about 20 to about $55 \mathrm{ng} / \mathrm{ml}$, were reached within a few days of the oestradiol peak. Plasma progesterone decreased in late pregnancy and in one of the three bitches studied in detail low or undetectable levels were reached 10 days before parturition. In the other two bitches an abrupt decrease in progesterone occurred just before parturition.

Dexamethasone treatment $(2 \times 5 \mathrm{mg}$ daily for 10 days) from Day 30 of pregnancy resulted in intrauterine death and resorption of the fetuses in the two bitches studied. Treatment from about Day 45 resulted in the birth of dead fetuses at Days 55 and 59 of pregnancy. The changes in plasma oestradiol levels were very small. No changes in plasma progesterone levels were seen when dexamethasone was given in late pregnancy, but an accelerated decline occurred after treatment in mid-pregnancy.
\end{abstract}

\section{Introduction}

The reported peripheral plasma levels of oestrogens in bitches during the oestrous cycle are conflicting, and the temporal relationship between the peak in plasma oestrogens and the onset of oestrus is not well established. Phemister, Holst, Spano \& Hopwood (1973) found maximal values for total oestrogens of $600-700 \mathrm{pg} / \mathrm{ml}$ of plasma during pro-oestrus. Bell, Christie \& YoungLai (1971) found that the maximal values occurred from early pro-oestrus to early oestrus and reported values of 63-75 pg total oestrogens $/ \mathrm{ml}$ plasma. On the other hand, Hadley (1973), assaying total free oestrogens, and Jones et al. (1973a, b), using a fairly specific oestradiol-17 $\beta$ antiserum, both found peak values as low as from about 17 to $37 \mathrm{pg} / \mathrm{ml}$ in the middle of the oestrous period. The discrepancies between the above-mentioned values cannot be fully explained by differences in the levels of oestradiol-17 $\beta$ and total free oestrogens.

In most mammals, plasma oestrogens increase during pregnancy (see Bedford, Challis, Harrison \& Heap, 1972). Jones et al. (1973b) reported a moderate increase in oestradiol-17ß levels in early pregnancy in the bitch and statistical analysis of their data shows a significant decrease in oestradiol$17 \beta$ from mid-pregnancy to term.

The object of the present study was to obtain further information on the changes in plasma oestrogen and progesterone concentrations during the oestrous cycle and pregnancy in the bitch. The effect of dexamethasone administration during pregnancy was also examined.

\section{Materials and Methods}

Seven pure-bred Labradors, about $1 \frac{1}{2}$ years of age at the start of the study, were kept in pens and fed twice daily. The bitches were checked daily for the presence of blood-stained mucus at the vulva 
to determine the onset of pro-oestrus. From the 5 th day of pro-oestrus the bitches were tested daily for acceptance of a fertile male and the first day of acceptance was designated as Day 1 of oestrus. The bitches were mated once only on the 3rd day of oestrus. The first day of refusal of the male was considered to be the last day of oestrus.

From late anoestrus through pro-oestrus, oestrus and pregnancy, daily blood samples were drawn from the cephalic vein at 10.00-12.00 hours into heparinized vacutainer tubes. The blood samples were centrifuged within $1 \mathrm{hr}$ of sampling and the plasma was stored at $-20^{\circ} \mathrm{C}$ until analysed.

Besides being studied during a normal oestrous cycle or pregnancy, three bitches (Nos 4, 12 and 16) were subjected to dexamethasone treatment, one (No. 16) during two consecutive pregnancies. Pregnancy was confirmed by deep palpation and the bitches given an i.m. injection of $5 \mathrm{mg}$ dexamethasone (Vorenvet: Astra, Södertälje, Sweden) twice daily for 10 days, starting at Day 30 after mating on two occasions and around Day 45 on two other occasions.

Plasma levels of oestradiol-17ß were measured by the radioimmunoassay technique described by Sundsfjord \& Aakvaag (1972) with a few minor modifications. Antiserum to oestradiol-17ß-6oxime bovine serum albumin was a gift from The Department of Medicine I, Royal Veterinary College, Stockholm. The antiserum was used in a dilution of $1: 250,000$ in a phosphate buffer, pH 7.4. The antiserum cross-reacted with oestrone to a degree of $11 \%$ (Lindberg, Lindberg, Martinsson \& Johansson, 1974).

Extractions of $1 \mathrm{ml}$ plasma and $1 \mathrm{ml}$ distilled water were carried out in duplicate with $20 \mathrm{ml}$ diethylether. The standard curves were prepared by assaying non-radioactive oestradiol-17 $\beta$ directly, without extraction from water or plasma. The figures obtained from the standard curves were corrected for experimental losses on the basis of the extraction efficiency obtained in each specific assay (range 74-84\%). The ether blank value, which was often zero, was deducted. The sensitivity of the assay as read off the standard curve was $2 \mathrm{pg}$, equivalent to a plasma concentration of $5 \mathrm{pg} / \mathrm{ml}$. A control plasma sample $(16.7 \pm 2 \cdot 8$ (S.D.) $\mathrm{pg} / \mathrm{ml}, n=25)$ was included in each assay. The mean recovery of 50 or $100 \mathrm{pg}$ oestradiol-17 $\beta$ added to plasma before extraction was $101.9 \pm 4.2 \%$ (S.D.).

No diurnal variations in plasma oestradiol-17 $\beta$ were found in the present study. When blood samples were taken every 2 nd hr throughout a 24 -hr period ( 4 bitches) the S.D. (2.89) of the oestradiol$17 \beta$ values within animals was close to that found by analyses of the control plasma. However, there were significant differences between animals in the concentration of oestradiol-17 $\beta$ during the 24-hr period $(P<0 \cdot 001)$.

The plasma concentration of progesterone was measured by the protein-binding technique described by Johansson (1969), as slightly modified by Fylling (1970). The progesterone results included in the present paper are part of a more extensive study by one of us (R.A.) of progesterone concentrations in bitches.

The variability of the values in the present paper is consistently given as a standard deviation (S.D.).

\section{Oestrous cycle}

\section{Results}

In some of the bitches only a few blood samples from the last part of the anoestrous period were available, but there appeared to be an increase in plasma oestradiol levels in late anoestrus (Text-figs 1 and 2).

The average interval between the onsets of pro-oestrus and oestrus in the present study was $7 \cdot 5$ days (range 5-10 days). During this period there was a marked increase in plasma oestradiol (Textfigs 1 and 2). Close to oestrus a well-defined peak in plasma oestradiol was demonstrable in all bitches, and the maximal concentration of plasma oestradiol $(79.7 \pm 10.9 \mathrm{pg} / \mathrm{ml})$ fell within 1 day of onset of oestrus, except for Bitch 12. Because of the large day-to-day fluctuations in plasma oestradiol during this period in some of the bitches, low values were possible on the day of onset of oestrus (Bitch 5, Text-fig. 2).

The peak of plasma oestradiol was followed by a rapid decrease and within 1-3 days after the peak the concentrations were of the same order as found in late anoestrus. The bitches exhibited oestrus for a considerable time after oestradiol levels had fallen to anoestrous values (Text-fig. 1). 

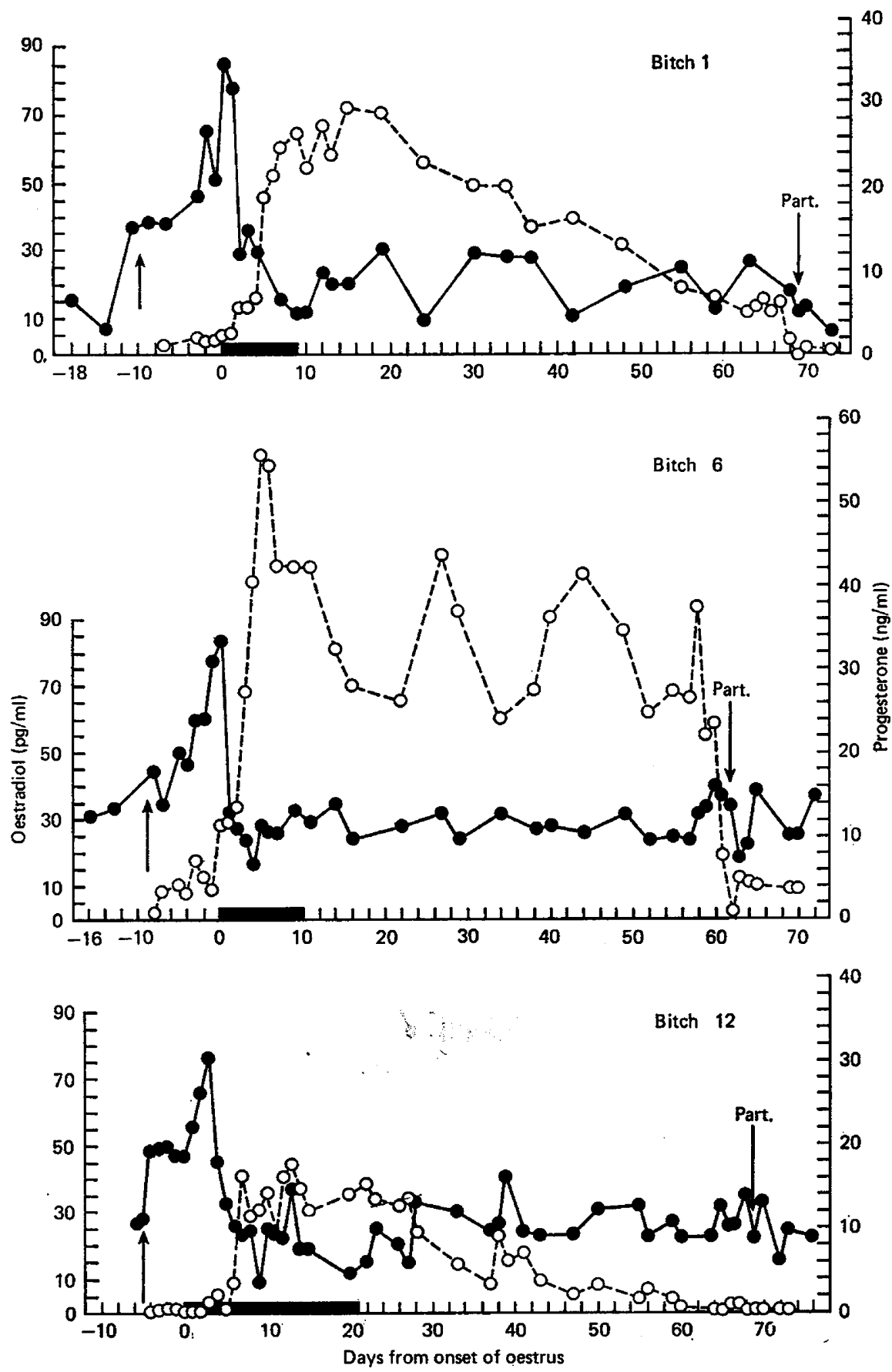

Text-fig. 1. The oestradiol-17 $\beta(\bullet)$ and progesterone $(O)$ concentrations in the peripheral plasma of three female Labradors during late anoestrus, pro-oestrus and pregnancy. The arrow denotes the start of pro-oestrus and the horizontal solid bar denotes the length of oestrus. Part. = parturition. 
Plasma progesterone levels did not change markedly during pro-oestrus in any of the three bitches, but varied considerably between animals (Text-fig. 1). From, or shortly after, the onset of oestrus, plasma progesterone started to rise and reached high values within a few days. In all bitches progesterone rose to high values while the bitch was still receptive to the male, and one (No. 12) stayed in oestrus for about 20 days although progesterone levels were high (Text-fig. 1).

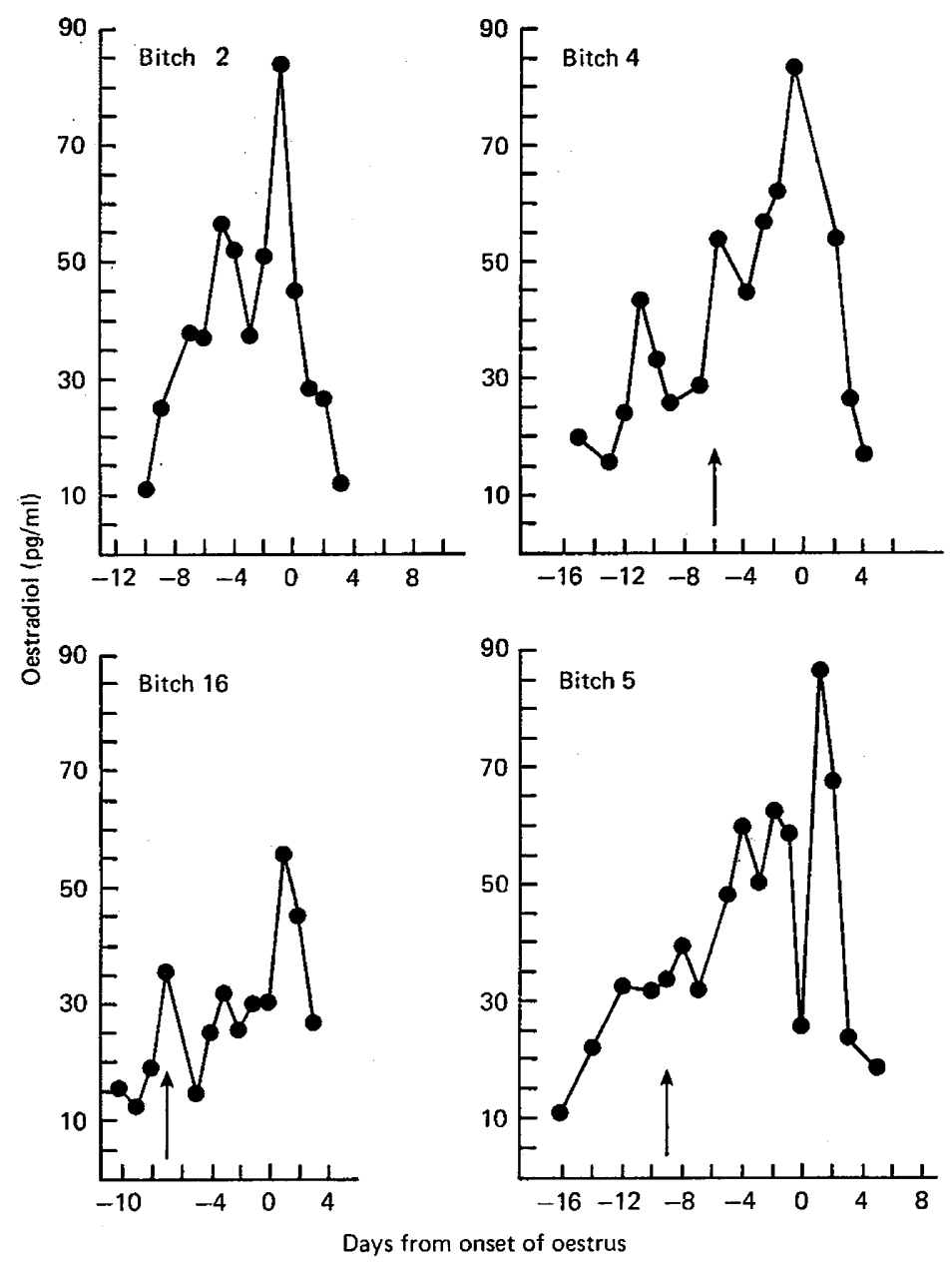

Text-fig. 2. Oestradiol-17 $\beta$ levels in the peripheral plasma during late anoestrus, pro-oestrus and oestrus in four Labrador bitches. The arrow denotes the start of pro-oestrus.

\section{Pregnancy}

Bitches 1 and 6 gave birth to six, and Bitch 12 to eight live puppies.

During pregnancy there were some fluctuations in plasma oestradiol but no general pattern was evident. In Bitches 1 and 12, the average concentrations of oestradiol from Days 5 to 24 after the oestrous peak $(16.2 \pm 6.1$ and $20.1 \pm 7.4 \mathrm{pg} / \mathrm{ml}$, respectively) were significantly lower $(P<0.01)$ than the corresponding values from Days 25 to $50(27 \cdot 2 \pm 4 \cdot 1$ and $28 \cdot 7 \pm 5 \cdot 8 \mathrm{pg} / \mathrm{ml}$, respectively). When the combined data for Bitches 1 and 12 for these periods were subjected to statistical analysis, 
the $P$ value was below 0.001. No such differences were found in Bitch $6(27 \cdot 2 \pm 5.4$ and $27 \cdot 4 \pm 3.4$ $\mathrm{pg} / \mathrm{ml}$ for the two periods, respectively).

No conspicuous change in plasma oestradiol was observed at the time of parturition, and no general trend for the first days after parturition could be demonstrated (Text-fig. 1).

The maximal concentrations, as well as the profile, of plasma progesterone during pregnancy differed greatly between the three bitches studied (Text-fig. 1). A relationship seemed to exist between plasma progesterone levels in pro-oestrus and pregnancy, the highest values in both periods being encountered in Bitch 6 and the lowest in Bitch 12. The concentration of progesterone during pregnancy fluctuated to a large degree. This was most pronounced in Bitch 6 . In late pregnancy the concentrations of progesterone decreased. In Bitch 12 very low, or undetectable, levels were reached about 10 days before parturition (Text-fig. 1), but in Bitches 1 and 6 there was an abrupt fall in plasma

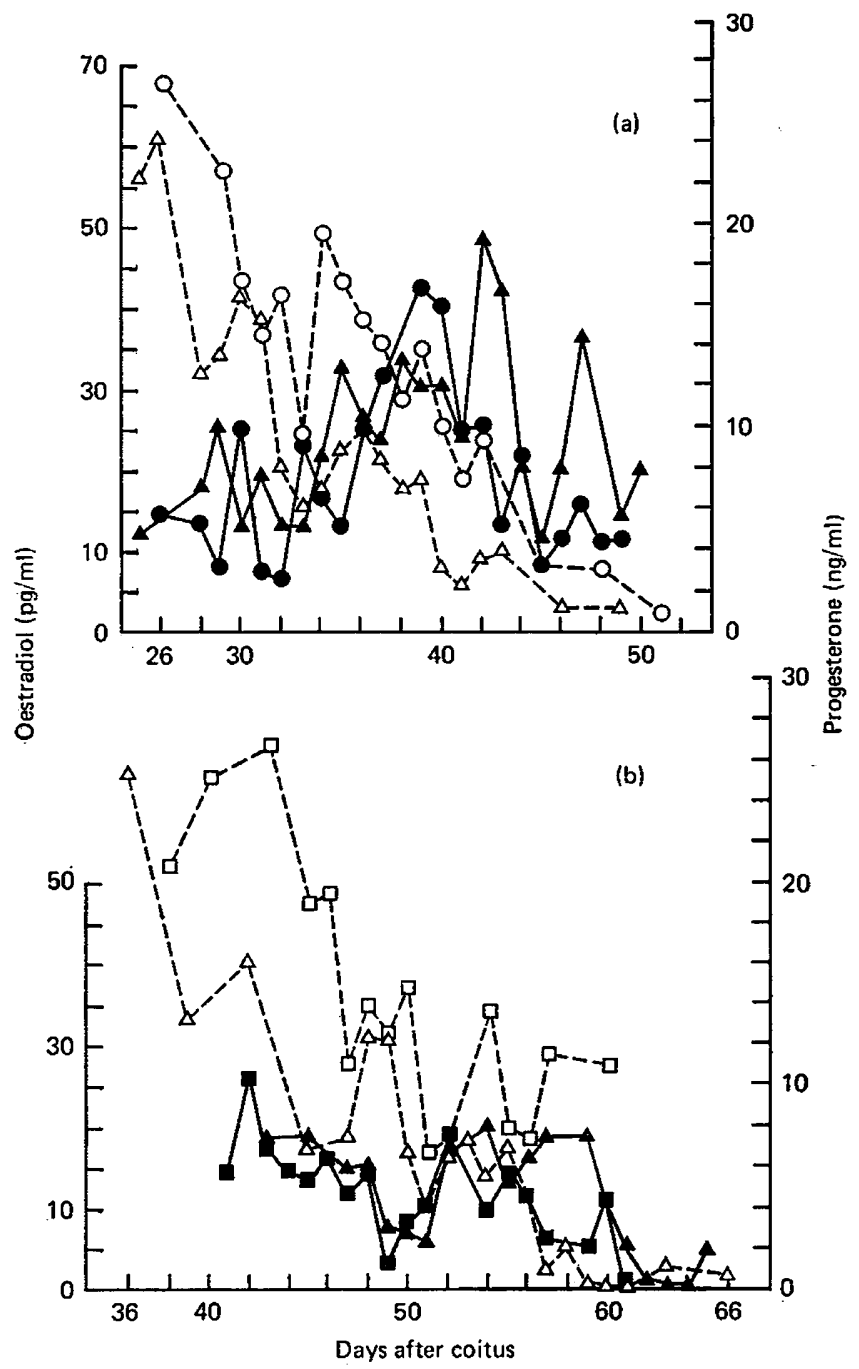

Text-fig. 3. Oestradiol-17 $\beta$ (solid symbols) and progesterone (open symbols) concentrations in the peripheral plasma before, during and after treatment with $5 \mathrm{mg}$ dexamethasone twice daily for 10 days. The treatment was started at (a) Day $30(\bullet, O$, Bitch $12 ; \Delta, \triangle$, Bitch 16) or (b) around Day 45 ( $\square, \square$, Bitch 4; $\Delta, \Delta$, Bitch 16 ) of pregnancy. 
progesterone in the last days of pregnancy. The magnitude of this pre-partum drop in plasma progesterone was much larger in Bitch 6 than Bitch 1.

\section{Dexamethasone treatment}

Treatment begun at Day 30 of pregnancy resulted in intrauterine death and resorption of the fetuses in both bitches. Reduction of the size of the embryos was evident a few days after treatment had been discontinued and at autopsy on Day 60 after mating fetal remains could not be seen. Treatment with dexamethasone at this stage of pregnancy seemed to increase the plasma concentration of oestradiol (Text-fig. 3a). In Bitch 12, however, maximal oestradiol concentrations were encountered after the treatment had been discontinued. Statistical comparison of the oestradiol values during the period of treatment with those of untreated bitches at the same stage of pregnancy was not performed because the general level was considerably lower in the treated bitches, even in the pretreatment period. Plasma progesterone levels decreased during the period of treatment. The quotient between the mean concentrations in the period of treatment and in a pretreatment period of 10 days was 0.46 in Bitch 16 and 0.65 in Bitch 12. The corresponding quotients for 9 untreated bitches were all above $0 \cdot 71$. The zero hypothesis, i.e. no difference between treated and untreated bitches, could therefore be rejected according to the Fisher-Irwin test $(P=0.02)$.

When treatment with dexamethasone was started around Day 45 of pregnancy, the bitches produced dead fetuses 1 and 3 days after the discontinuance of treatment, corresponding to Days 55 and 59 of pregnancy, respectively (Text-fig. 3b). The mean gestation length of 16 untreated Labrador bitches was $62 \cdot 3 \pm 2 \cdot 9$ days (range 58-68 days). The plasma oestradiol fluctuated during the period of treatment and no definite pattern was observed. After parturition the oestrogens fell gradually to very low or undetectable levels. Plasma progesterone decreased slightly during the period of treatment, but this decrease, as analysed by the Fisher-Irwin test, was not significantly different from the decrease found in 9 untreated controls.

\section{Discussion}

All the bitches examined in the present study exhibited a well-defined peak of oestradiol-17 $\beta$ concentration in peripheral plasma around the onset of oestrus. The mean maximal concentration of $79 \cdot 7 \pm 10 \cdot 9$ (S.D.) $\mathrm{pg} / \mathrm{ml}$, is considerably higher than the maximal oestradiol-17 $\beta$ values found by Jones et al. (1973a, b) and also higher than the values for total oestrogens found by Hadley (1973). The values obtained in the present study are, however, in the same range, although slightly higher, than those reported for total oestrogens by Bell et al. (1971). The reason for the higher values of plasma oestrogens found in bitches in the present study is unknown. The antiserum used was specific for oestradiol-17ß (Lindberg et al., 1974) and plasma samples from ovariectomized bitches gave values below $3 \mathrm{pg} / \mathrm{ml}$. It is thus not very likely that the values in the present study should be erratically high due to imperfections in the analytical technique. It is also unlikely that the discrepancies between values obtained in different studies should be due to differences in feeding or between breeds.

Although blood samples were not taken more frequently than every $24 \mathrm{hr}$, the peaks of plasma oestradiol varied by less than $10 \mathrm{pg} / \mathrm{ml}$ in $6 / 7$ bitches examined (Text-figs 1 and 2). This argues against the existence of oestrogen peaks of very short duration superseding the 24-hr maxima.

Contrary to the findings of Hadley (1973), the present study indicates a moderate rise in oestrogens in the last part of anoestrus.

Phemister et al. (1973) and Holst \& Phemister (1971) found that ovulation in bitches takes place from 1-2 days after the onset of oestrus, coinciding with the occurrence of the LH peak (Jones et al., 1973a). The demonstration of a distinct oestradiol peak close to the onset of oestrus in the present study supports the hypothesis of Jones et al. (1973a) that the increase in oestrogens stimulates the release of LH. Plasma oestrogens must have decreased to rather low levels in some bitches (Text-figs 1 and 2) at the time when ovulation probably occurred, and accords with findings for other species (Short, 1972). In sheep, McCracken, Glew \& Levy (1970) detected a brief secondary peak of 
oestradiol-17 $\beta$ in utero-ovarian venous plasma which coincided with the rise in $\mathrm{LH}$. The results of the present study argue against the existence of such a peak in the bitch.

A large increase in oestradiol during pro-oestrus was evident in all bitches in the present study, supporting the belief that increase in oestrogens is responsible for the induction of oestrus in the bitch. In sheep (McCracken et al., 1970) and cows (Glencross, Munro, Senior \& Pope, 1973), a time-lag between increased oestrogen secretion and the appearance of oestrus has been reported. The present data indicate that such a lag also exists in the bitch, since the plasma concentrations of oestradiol on some occasions were falling before the bitch showed oestrus (Text-fig. 2). In some mammals, increased levels of progesterone also seem to be essential for the induction of oestrus (Short, 1972). In sheep and rats, high concentrations of progesterone precede and follow, respectively, the preovulatory peak of oestrogens. In the bitch, high concentrations of progesterone do not seem to be necessary for the induction of oestrus. Moreover, the bitch remains in oestrus for a considerable period while there are high concentrations of circulating progesterone (Jones et al., 1973a; Phemister et al., 1973; Smith \& McDonald, 1974; present study), as does the fox (O. M. Møller, A. Lunde, J. Aursjø \& Ø. V. Sjaastad, unpublished). The persistence of oestrus in the absence of high levels of oestrogens and in the presence of high levels of progesterone does not seem to be characteristic for animals exhibiting a long oestrous period. In the mare, a long oestrous period is associated with low levels of progesterone (Stabenfeldt, Hughes \& Evans, 1972) and high levels of oestrogens (Pattison, Chen \& King, 1972).

In most species there is an increase in oestrogen concentrations during pregnancy (Bedford et al., 1972). Jones et al. (1973a) reported a significant increase in oestradiol levels during the first half of pregnancy in the bitch. In the present study, oestradiol was found to be significantly higher in midpregnancy than in the period following oestrus in two of the three bitches examined. Since such a change was not found in the third bitch, the importance of this observation may be questioned. Although other explanations are possible, the moderate and inconsistent changes of oestradiol found during pregnancy in the present study probably indicate that oestrogens are not produced to any large extent, if at all, by the feto-placental system in the bitch. Marked changes in oestradiol levels are also absent in the fox during pregnancy (O.M. Møller, A. Lunde, J. Aursjø \& Ø. V. Sjaastad, unpublished).

The contribution of oestrogens and progesterone in the process of triggering parturition is not yet clear. The hypothesis of a withdrawal of a progesterone block of the myometrium as a trigger is not supported by findings in the present study. Although there was a fall in plasma progesterone in the last part of pregnancy the fall was not precipitous in all animals: in Bitch 12 undetectable values were reached as much as 10 days before whelping. Increased myometrial activity in late pregnancy coincides with the time when oestrogens in peripheral plasma reach maximal values (Heap, 1972). In the bitch, however, the absence of major changes in oestradiol concentration in late pregnancy and the inconsistency of the pre-partum drop in progesterone level, as observed in the present study, may indicate that factors other than oestrogens and progesterone are responsible for the induction of parturition, although the concentration in peripheral plasma gives little information of the dynamics and utilization of any hormone.

Synthetic corticoids have been found to induce mid-term abortion (Fylling, Sjaastad \& Velle, 1973) as well as premature parturition (see van Rensburg, 1967; Fylling, 1971) in sheep and cows (see Adams, 1969; Edqvist et al., 1972) but not pigs (Bosu, Edqvist \& Gustaffsson, 1974). When premature parturition was induced by dexamethasone in cows in the last part of pregnancy an increase in plasma oestrogens and a decrease in plasma progesterone was observed (Edqvist et al., 1972). Dexamethasone given in early or mid-pregnancy resulted in dead fetuses but no change in oestrogens and a decline in progesterone levels in only some of the cows (Edqvist et al., 1972). In the present study dexamethasone treatment in late pregnancy resulted in possibly premature parturition of dead fetuses, but had no significant effect on the plasma level of oestradiol or progesterone. Treatment with dexamethasone in mid-pregnancy resulted in dead fetuses, a moderate increase in oestradiol and an apparently accelerated decline in plasma progesterone levels as compared with those of untreated controls. Since there are marked fluctuations in both hormones, however, and since only two bitches were examined, these findings must be considered as preliminary. 


\section{References}

Adams, W.M. (1969) The elective induction of labor and parturition in cattle. J. Am. vet. med. Ass. 154, 261.

Bedford, C.A., Challis, J.R.G., Harrison, F.A. \& HeAP, R.B. (1972) The rôle of oestrogens and progesterone in the onset of parturition in various species. $J$. Reprod. Fert., Suppl. 16, 1-23.

Bell, E.T., Christie, D.W. \& Younglai, E.V. (1971) Plasma oestrogen levels during the canine oestrous cycle. $J$. Endocr. 51, 225-226.

Bosu, W.T.K., EdQvist, L.E. \& Gustafsson, B. (1974) Peripheral plasma levels of estrone and progesterone in pregnant pigs treated with dexamethasone. Acta vet. scand. 15, 111-119.

EdQvist, L.-E., EkMAN, L., GuSTAFSSON, B., JACOBSSON, S.-O., Johansson, E.D.B. \& Lindell, J.-O. (1972) Peripheral plasma levels of oestrone and progesterone in pregnant cows treated with dexamethasone. Acta endocr., Copenh. 71, 731-742.

Fylling, P. (1970) The effect of pregnancy, ovariectomy and parturition on plasma progesterone level in sheep. Acta endocr., Copenh. 65, 273-283.

Fylling, P. (1971) Premature parturition following dexamethasone administration to pregnant ewes. Acta endocr., Copenh. 66, 289-295.

Fylling, P., SuaAstad, Ø.V. \& Velle, W. (1973) Mid-term abortion induced in sheep by synthetic corticoids. J. Reprod. Fert. 32, 305-306.

Glencross, R.G., Munro, I.B., Senior, B.E. \& Pope, G.S. (1973) Concentrations of oestradiol-17 $\beta$, oestrone and progesterone in jugular venous plasma of cows during the oestrous cycle and in early pregnancy. Acta endocr., Copenh. 73, 374-38-.

HADLEY, J.C. (1973) Variations in peripheral blood concentrations of progesterone and total free oestrogens in the non-pregnant bitch. Vet. Rec. 93, 77.

HeAP, R.B. (1972) Role of hormones in pregnancy. In Reproduction in Mammals, Book 3, pp. 73-104. Eds C. R. Austin \& R. V. Short. Cambridge University Press, London.

Holst, P.A. \& Phemister, R.D. (1971) The prenatal development of the dog: preimplantation events. Biol. Reprod. 5, 194-206.

Johansson, E.D.B. (1969) Progesterone levels in peripheral plasma during the luteal phase of the human menstrual cycle measured by a rapid competitive protein binding technique. Acta endocr., Copenh. 61, 592-600.

Jones, G.E., Boyns, A.R., Cameron, E.H.D., Bell, E.T., Christie, D.W. \& Parkes, M.F. (1973a) Plasma oestradiol, luteinizing hormone and progesterone during the oestrous cycle in the beagle bitch. J. Endocr. 57, 331-332.

Jones, G.E., Boyns, A.R., Cameron, E.H.D., Bell, E.T., Christie, D.W. \& Parkes, M.F. (1973b) Plasma oestradiol, luteinizing hormone and progesterone during pregnancy in the beagle bitch. $J$. Reprod. Fert. 35, 187-189.

Lindberg, B.S., Lindberg, P., Martinsson, K. \& JoHANSSON, E.D.B. (1974) Radioimmunological methods for the estimation of oestrone, oestradiol$17 \beta$ and oestriol in pregnancy plasma. Acta obstet. gynec. scand., Suppl. 32, 5-19.

MCCracken, J.A., Glew, M.E. \& LeVy, L.K. (1970) Regulation of corpus luteum function by gonadotropins and related compounds. Adv. Biosci. 4, 377.

Pattison, M.L., Chen, C.L. \& King, S.L. (1972) Determination of L.H. and estradiol-17ß surge with reference to the time of ovulation in mares. Biol. Reprod. 7, 136, Abstr.

Phemister, R.D., Holst, P.A., Spano, J.S. \& Hopwood, M.L. (1973) Time of ovulation in the beagle bitch. Biol. Reprod. 8, 74-82.

ShoRT, R.V. (1972) Role of hormones in sex cycles. In Reproduction in Mammals, Book 3, pp. 42-72. Eds C. R. Austin \& R. V. Short. Cambridge University Press, London.

SMITH, M.S. \& MCDonald, L.E. (1974) Serum levels of luteinizing hormone and progesterone during the estrous cycle, pseudopregnancy and pregnancy in the dog. Endocrinology 94, 404-412.

Stabenfeldt, G.H., Hughes, J.P. \& Evans, J. (1972) Ovarian activity during the estrous cycle of the mare. Endocrinology 90, 1379-1384.

SundsfJoRd, J.A. \& AAKVAAG, A. (1972) Plasma renin activity, plasma renin substrate and urinary aldosterone excretion in the menstrual cycle in relation to the concentration of progesterone and oestrogens in the plasma. Acta endocr., Copenh. 71, 519-529.

VAN ReNsBURG, S.J. (1967) Gestation in sheep after foetal adrenalectomy and cortisol acetate administration. J. Endocr. 38, 83-84. 